\title{
Primary Laryngeal Tuberculosis as a Cause of Persistent Hoarseness-A Case Report
}

\author{
Akinola Moses Ayodele1, Olusoga-Peters Oluwapelumi'1, Bamigboye Babatunde², \\ Binuyo Tolulope ${ }^{1}$, Somefun Abayomi²
}

\author{
${ }^{1}$ Department of Surgery, Ben Carson College of Health and Medical Sciences, Babcock University, Ilishan-Remo, Nigeria \\ ${ }^{2}$ Department of Surgery, College of Medicine, University of Lagos, Lagos, Nigeria \\ Email: ayoakinol12@gmail.com
}

How to cite this paper: Ayodele, A.M., Oluwapelumi, O.-P., Babatunde, B., Tolulope, B. and Abayomi, S. (2021) Primary Laryngeal Tuberculosis as a Cause of Persistent Hoarseness-A Case Report. Case Reports in Clinical Medicine, 10, 220-225. https://doi.org/10.4236/crcm.2021.108028

Received: July 16, 2021

Accepted: August 16, 2021

Published: August 19, 2021

Copyright $\odot 2021$ by author(s) and Scientific Research Publishing Inc. This work is licensed under the Creative Commons Attribution International License (CC BY 4.0).

http://creativecommons.org/licenses/by/4.0/

\section{Open Access}

\begin{abstract}
Laryngeal tuberculosis is an uncommon disease of the larynx that can easily be missed. It is however the commonest granulomatous laryngeal pathology. Laryngeal tuberculosis and laryngeal cancer both have similar modes of clinical presentation. We present a case of isolated laryngeal tuberculosis in a 38-year-old Nigerian female, who presented with persistent hoarseness of 3 months duration with no respiratory symptoms and signs. Fiberoptic laryngoscopy showed hyperemia and oedema of the endolarynx, mucoid exudate and thickening of both false and true vocal cords. Tuberculosis was confirmed by gene Xpert. She was placed on rifampicin, isoniazid, pyrazinamide and ethambutol for two months intensive phase and rifampicin and isoniazid for four months continuation phase. There was complete resolution of hoarseness after completion of anti-tuberculous therapy.
\end{abstract}

\section{Keywords}

Laryngeal Tuberculosis, Hoarseness, Gene Xpert, Fiberoptic Laryngoscopy

\section{Introduction}

Mycobacterium tuberculosis (MTB) is the causative organism of tuberculosis (TB) and is spread when sick individuals with TB expel the bacteria into the air while coughing, talking or laughing. TB typically affects the lungs but the disease can also affect other sites apart from the lungs (extrapulmonary tuberculosis).

Tuberculosis is curable and preventable as most individuals (about 85\%) who develop it can be successfully treated with a 6-month drug regimen which has an additional benefit of reducing further transmission of infection [1].

Laryngeal tuberculosis is an uncommon disease and can be easily missed [2] 
especially because physical examination findings are usually nonspecific [3]. It is however the commonest granulomatous laryngeal pathology and usually affects males between the $4^{\text {th }}$ and $6^{\text {th }}$ decade of life. Smoking, human immunodeficiency virus (HIV), use of recreational and immunosuppressive drugs and malignancy are factors associated with development of TB in the upper respiratory tract [4].

Laryngeal TB and laryngeal carcinoma both have similar modes of clinical presentation as progressive dysphonia is a symptom which is present in both. Furthermore, they both have similar looking lesions on laryngoscopy [5] [6] [7].

Laryngeal infections usually involve structures of the anterior larynx and are often characterized by hypertrophic, exophytic and/or polypoid lesions. There is affectation of both true and false vocal cords in about 50\% - 70\% and $40 \%-50 \%$ respectively. These major structures can cause airway inflammation and obstruction from severe infections which may lead to respiratory distress and respiratory arrest if not properly managed [8].

Laryngeal and pulmonary TB infections usually occur concurrently and laryngeal examinations are not often performed routinely; thus, only pulmonary infections end up being diagnosed thereby, missing concurrent laryngeal TB infections. This indicates that the incidence of laryngeal TB cases is grossly underreported [9] [10].

The aim of this case report is to present a rare case of primary laryngeal tuberculosis in an environment where pulmonary tuberculosis is very common.

\section{Case Presentation}

We present a 38 year old woman who presented to the clinic on account of cough and progressive hoarseness of three months duration. Cough was productive of thick, frothy sputum. It was non paroxysmal, not associated with wheezing, chest pain or difficulty in breathing. Cough was worse at night, with no known exacerbating or relieving factors and not associated with fever, chills or rigor. There was no history of hemoptysis. There was weight loss evidenced by loosening of her clothes. Patient had contact with her apprentice who had undergone treatment for TB some time ago (duration could not be ascertained).

There was no history of voice overuse. She takes omeprazole and antacids regularly to control symptoms of peptic ulcer disease (PUD). No previous history of head and neck surgery, she neither smokes cigarette nor takes alcohol. Patient had no history of ear pain or discharge, sore throat, painful or difficulty swallowing, no history of hemoptysis or epistaxis.

At the onset of symptoms, she used over the counter medications (antibiotics and cough syrup) which gave no relief of symptoms, necessitating her presentation to our facility.

On Examination: She was chronically ill looking, not pale, anicteric, afebrile, not cyanosed, not dehydrated, not cyanosed, no pedal edema.

Respiratory rate was 20 cycles per minute and breath sounds were vesicular.

Physical examination of ear, nose and oropharynx were essentially normal. 
Chest X ray showed no evidence of pulmonary involvement (Figure 1).

Gene Xpert: Positive for mycobactarium tuberculosis (MTB) with intermediate RIF resistance index.

HIV: Not reactive

Fibreoptic laryngoscopy: hyperemia and edema of the laryngeal mucosa with thickening of both true and false vocal cords which is worse on the left. There was narrowing of the anterior commissure and incomplete closure of the glottis. Mucoid exudate was seen in the supraglottic and glottic areas. Both vocal cords were mobile (Figure 2).

Patient was commenced on RIPE (Rifampicin, Isoniazid, Pyrazinamide and Ethambutol) regimen which she had for two months (intensive phase).

Rifampicin $150 \mathrm{mg}$ daily

Isoniazid $75 \mathrm{mg}$ daily

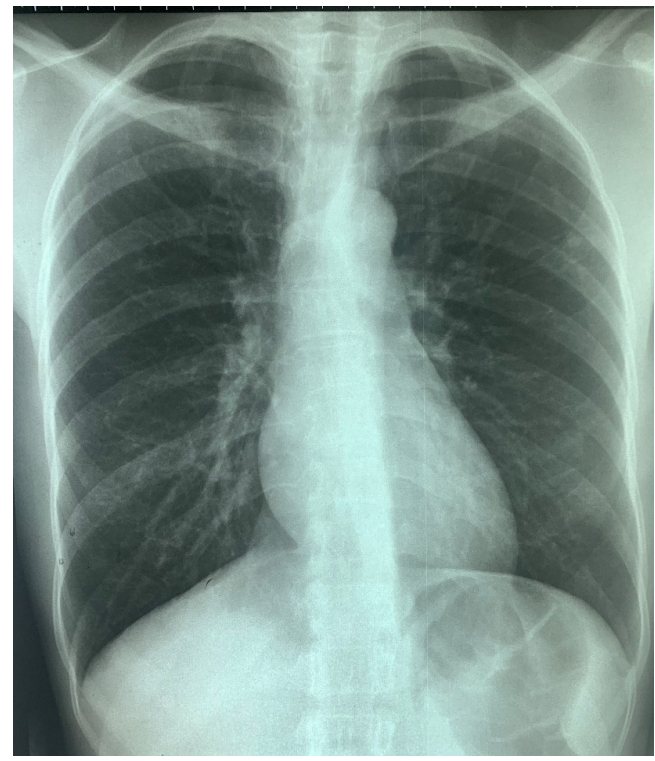

Figure 1. Chest $\mathrm{x}$ ray with no evidence of pulmonary tuberculosis.

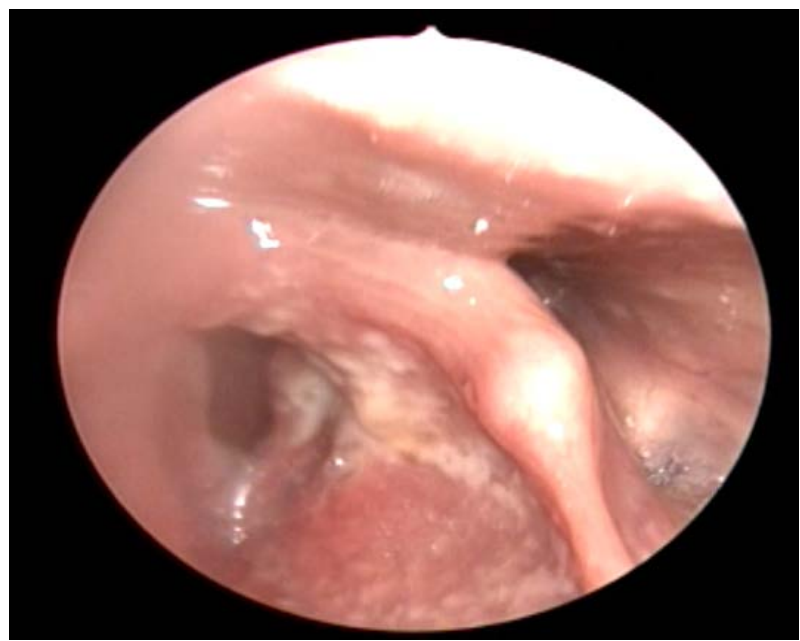

Figure 2. Showing edematous and inflamed vocal cords. 
Pyrazinamide $400 \mathrm{mg}$ daily

Ethambutol 275 mg daily

She then proceeded to continuation phase (rifampicin $150 \mathrm{mg}$ and isoniazid $75 \mathrm{mg}$ daily) for four months.

There was no MTB detected by gene Xpert after the completion of continuation phase of anti-tuberculous medication.

Repeat laryngoscopy done after completion of 6 months of anti-tuberculous drugs: essentially normal (Figure 3).

\section{Discussion}

The most prevalent laryngeal granulomatous disease is laryngeal TB [11]. Laryngeal tuberculosis can be divided into two classes: primary (with no pulmonary involvement) or secondary (with pulmonary involvement). Mode of transmission of laryngeal TB is usually by hematogenous, lymphatic or bronchogenic spread from the lungs. In some cases, laryngeal TB may be the primary lesion which indicates that the bacilli were probably inhaled directly and that there are no pulmonary lesions [12].

The commonest presenting complaints in people with laryngeal TB are hoarseness and odynophagia, which occurs in about $80 \%-100 \%$ of cases [13] [14] [15]. Other complaints present in laryngeal TB patients are dysphagia, dyspnea, stridor, cough and hemoptysis [16]. Laryngeal lesions on laryngoscopy are nonspecific because laryngeal TB lesions may appear similar to that of leukoplakia, reflux laryngitis, laryngeal polyps, contact ulcer and laryngeal cancer [17].

In patients in regions with high $\mathrm{TB}$ endemicity presenting with chronic odynophagia, weight loss and hoarseness, a possibility of Laryngeal TB should be entertained so as to prevent delay in diagnosis and treatment. Laryngeal TB may also be misdiagnosed in areas where TB is not endemic as its lesions are non-specific and similar to lesions seen in laryngeal malignancy. Furthermore,

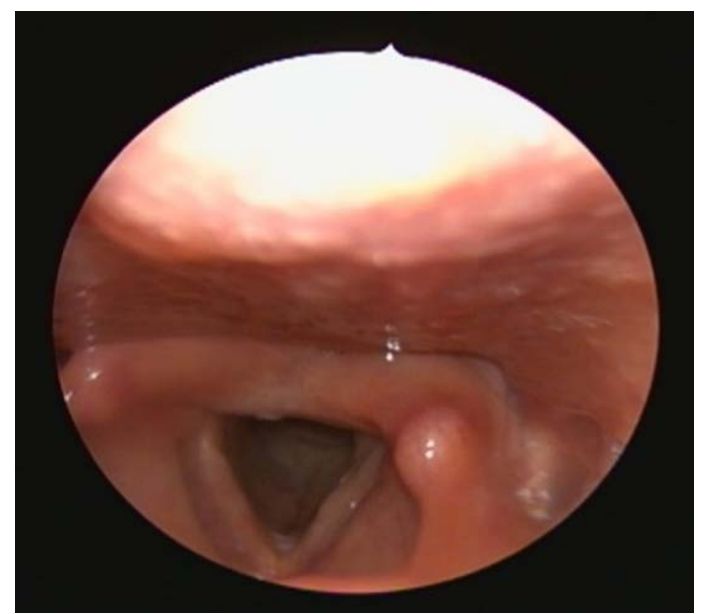

Figure 3. Showing normal findings on repeat laryngoscopy done after completion of anti TB regimen. 
laryngeal cancers usually present in older patients. Granulomatosis with polyangitis, sarcoidosis and syphilis are other granulomatous diseases that may present with lesions involving the larynx [18].

Chest radiography or chest computerized tomography (CT) is the appropriate initial investigation in the evaluation of patients with suspected laryngeal TB with pulmonary involvement. A case series carried out in the United States between 1970 and 2012 on 127 people with laryngeal TB revealed that $86 \%$ of those cases recorded radiographic findings suggestive of pulmonary TB [11]. Hoarseness, cough and dysphagia were the commonest presenting complaints of patients in the US study mentioned earlier which is similar to this case presentation as the index patient presented with hoarseness and cough although a chest CT was not done. However, there was no evidence of pulmonary tuberculosis in this patient from her chest $\mathrm{x}$ ray.

The World Health Organization (WHO) guideline for treatment of tuberculosis states that patients should undergo six-month regimen (2RHZE/4RH) which means an intensive phase for 2 months consisting of rifampicin $(\mathrm{R})$ and isoniazid $(\mathrm{H})$, pyrazinamide $(\mathrm{Z})$ and ethambutol $(\mathrm{E})$ and a continuation phase for four months of rifampicin $(\mathrm{R})$ and isoniazid $(\mathrm{H})$ [19].

A study carried out in Kenya among five patients with confirmed laryngeal TB showed that after 18 weeks of treatment with anti Kochs, the larynx returned to its normal appearance [20]. This was the case in our patient as fibreoptic laryngoscopy done after completion of 6 months regimen of antituberculous drugs revealed that the laryngeal lesions had disappeared and the larynx was back to normal (Figure 3).

\section{Conclusion}

Laryngeal tuberculosis should be a differential diagnosis in any patient presenting with hoarseness. Diagnosis requires a high index of suspicion as laryngeal TB presentation is similar to that of laryngeal cancer. Delay in diagnosis poses a significant public health risk to the patient, health workers and the general population.

\section{Conflicts of Interest}

The authors declare no conflicts of interest regarding the publication of this paper.

\section{References}

[1] World Health Organization (2020) Global Tuberculosis Report 2020. WHO Press, Geneva.

[2] Matsuura, H. and Yamaji, Y. (2017) Laryngeal Tuberculosis: A Forgotten Disease. QJM: An International Journal of Medicine, 110, 521. https://doi.org/10.1093/qjmed/hcx078

[3] Paulauskienè, I. and Mickevičienè, V. (2016) Dysphonia-The Single Symptom of Rifampicin Resistant Laryngeal Tuberculosis. Open Medicine, 11, 63-67. 
https://doi.org/10.1515/med-2016-0013

[4] Jindal, S.K., Jindal, A., Agarwal, R., et al. (2016) Upper Respiratory Tract Tuberculosis. Microbiology Spectrum, 4.

[5] Suhail, A., Ahmed, M.S., Sobani, Z.U. and Ghaffar, S. (2012) Laryngeal Tuberculosis Presenting as Laryngeal Carcinoma. Journal of Pakistan Medical Association, 62, 167-168. http://jpma.org.pk/full article text.php?article id=3261

[6] Lucena, M.M., da Silva, F.D., da Costa, A.D., et al. (2015) Evaluation of Voice Disorders in Patients with Active Laryngeal Tuberculosis. PLoS ONE, 10, e0126876.

[7] Ling, L., Zhou, S.H. and Wang, S.Q. (2010) Changing Trends in the Clinical Features of Laryngeal Tuberculosis: A Report of 19 Cases. International Journal of Infectious Diseases, 14, 230-235.

[8] Frerk, C., Mitchell, V.S., McNarry, A.F., et al. (2015) Difficult Airway Society 2015 Guidelines for Management of Unanticipated Difficult Intubation in Adults. British Journal of Anaesthesia, 115, 827-848. https://doi.org/10.1093/bja/aev371

[9] Reis, J.G., Reis, C.S., da Costa, D.C., et al. (2016) Factors Associated with Clinical and Topographical Features of Laryngeal Tuberculosis. PLOS ONE, 11, e0153450.

[10] Pang, P., Duan, W., Liu, S., et al. (2018) Clinical Study of Tuberculosis in the Head and Neck Region-11 Years' Experience and a Review of the Literature. Emerging Microbes \& Infections, 7, 4. https://doi.org/10.1038/s41426-017-0008-7

[11] Benwill, J.L. and Sarria, J.C. (2014) Laryngeal Tuberculosis in the United States of America: A Forgotten Disease. Scandinavian Journal of Infectious Diseases, 46, 241-249.

[12] Lim, J.Y., Kim, K.M., Choi, E.C., Kim, Y.H., Kim, H.S. and Choi, H.S. (2006) Current Clinical Propensity of Laryngeal Tuberculosis: Review of 60 Cases. European Archives of Oto-Rhino-Laryngology, 263, 838-842.

[13] Shin, J.E., Nam, S.Y., Yoo, S.J. and Kim, S.Y. (2000) Changing Trends in Clinical Manifestations of Laryngeal Tuberculosis. Laryngoscope, 110, 1950-1953.

[14] Cengiz, A., Göksel, S., Başal, Y., Taş Gülen, Ş., Döğer, F. and Yürekli, Y. (2018) Laryngeal Tuberculosis Mimicking Laryngeal Carcinoma on 18F-FDG PET/CT Imaging. Molecular Imaging and Radionuclide Therapy, 27, 81-83.

[15] Agarwal, R., Gupta, L., Singh, M., Yashaswini, N., Saxena, A., Khurana, N. and Chaudhary, D. (2019) Primary Laryngeal Tuberculosis: A Series of 15 Cases. Head and Neck Pathology, 13, 339-343.

[16] Smulders, Y.E., De Bondt, B.J., Lacko, M., Hodge, J.A. and Kross, K.W. (2009) Laryngeal Tuberculosis Presenting as a Supraglottic Carcinoma: A Case Report and Review of the Literature. Journal of Medical Case Reports, 3, 9288.

[17] Kandiloros, D.C., Nicolopoulos, T.P., Ferekidis, E.A., et al. (1997) Laryngeal Tuberculosis at the End of the 20th Century. The Journal of Laryngology \& Otology, 111, 619-621. https://doi.org/10.1017/S0022215100138137

[18] Nwawka, O.K., Nadgir, R., Fujita, A. and Sakai, O. (2014) Granulomatous Disease in the Head and Neck: Developing a Differential Diagnosis. Radiographics, 34, $1240-1256$.

[19] World Health Organisation (2010) Treatment of Tuberculosis Guidelines. 4th Edition, World Health Organization, Geneva.

[20] Topak, M., Oysu, C., Yelken, K., Sahin-Yilmaz, A. and Kulekci, M. (2008) Laryngeal Involvement in Patients with Active Pulmonary Tuberculosis. European Archives of Oto-Rhino-Laryngology, 265, 327-330. https://doi.org/10.1007/s00405-007-0459-x 